\title{
Healthcare-Associated Viral Infections: Considerations for Nosocomial Transmission and Infection Control
}

\author{
Gail J. Demmler-Harrison
}

\section{Introduction}

Viral infections are extremely common in children. Given the frequency with which they occur in the general pediatric population, as well as the prolonged period of shedding associated with many viruses, it is not surprising that these agents may pose a risk for transmission within the healthcare environment. This chapter will briefly review common and clinically significant viral pathogens with the potential for healthcare-associated transmission as well as infection control considerations related to these infections. In addition, isolation and containment procedures related to rare but highly virulent viral pathogens will be discussed.

\section{Respiratory Viruses}

Respiratory viruses are common healthcare-associated viral infections, especially in pediatric hospitals or health centers where children are seen, evaluated, and treated [1-6]. Respiratory virus nucleic acids were detected in $42 \%$ of samples taken from environmental surfaces in a children's hospital waiting room in one study [7]. The respiratory viruses of major importance to healthcare-associated infections are usually considered to include the paramyxoviruses (such as respiratory syncytial virus (RSV); parainfluenza viruses types 1, 2, 3, and 4; and human metapneumovirus); the orthomyxoviruses, including influenza A and B; the picornaviruses, some of which can be transmitted from the respiratory tract, such as rhinoviruses and respiratory enteroviruses; and the respiratory adenoviruses, of which

\footnotetext{
G. J. Demmler-Harrison

Department of Pediatrics, Baylor College of Medicine, Houston, TX, USA

Infectious Diseases Service, Texas Children's Hospital, Houston, TX, USA

e-mail: gdemmler@bcm.edu
} 
there are many serotypes. Mimiviruses also may cause nosocomial pneumonia, especially in patients who are being mechanically ventilated in intensive care units. Respiratory virus infections may have potentially fatal consequences in children with hematologic malignancies or who have received bone marrow transplants. Therefore prompt isolation upon admission of patients with suspected respiratory viral infections, prior to confirmatory diagnosis, should be routine in healthcare centers to reduce nosocomial spread. In addition to contact precautions that have been traditionally recommended for many respiratory virus infections, enhanced isolation precautions (adding droplet precautions to contact precautions) have recently been shown to reduce the rate of nosocomial respiratory virus infections in pediatric hospitals and have now been adopted by many centers, especially bone marrow transplant units [1]. In such scenarios, caretakers wear gowns, gloves, and surgical masks during patient care encounters to reduce nosocomial spread of respiratory viruses. Therapy for the vast majority of respiratory viral infections in children, even in cases of hospital-acquired disease, is supportive with supplemental fluid and oxygen administered as needed and mechanical ventilation in cases of respiratory failure. Considerations related to specific viruses will be discussed below along with appropriate antiviral therapy when relevant.

\section{Respiratory Syncytial Virus}

Respiratory syncytial virus (RSV), an enveloped, RNA, paramyxovirus, causes acute respiratory tract infections and is probably the most common healthcareassociated viral infection in the pediatric setting [8-10]. Infection with RSV may occur at any age, although it is most frequently diagnosed in the first 2 years of life. Reinfections with RSV may occur. It causes upper respiratory tract symptoms, such as rhinorrhea (often copious in nature), cough, and otitis media, as well as lower respiratory tract disease, such as bronchiolitis and pneumonia. In newborns or premature infants, apnea may be a presenting symptom. Most infections with RSV occur during the fall and early winter, but there are annual and regional differences to the start and finish of each RSV season. Most RSV infections are self-limited; however, infection may cause serious, even life-threatening disease in medically fragile patients, such as those with congenital heart disease, neuromuscular disease, and/or immunocompromised hosts. RSV is a common cause for medical visits in clinics, urgent care centers, and emergency centers, as well as hospitalization in acute care and intensive care units, providing ample opportunity for nosocomial transmission. Nosocomial outbreaks in pediatric wards, pediatric intensive care units, bone marrow transplant units, and neonatal intensive care units have been reported $[8,10,11]$ and are associated with prolonged hospitalizations, prolonged time receiving mechanical ventilation, and even increased mortality.

The diagnosis of RSV can be suspected clinically with reasonable reliability in an infant or child with bronchiolitis occurring during local "RSV season" and established definitively by point-of-care rapid diagnostic tests (POCT) frequently 
used in clinics and urgent care centers. Traditional viral culture or respiratory viral panels utilizing molecular diagnostics are alternative means of virologic diagnosis.

The treatment of RSV infection is usually supportive in normal hosts, with fluid and respiratory support and suctioning of the nose and airways as needed. Antiviral treatment with inhaled ribavirin may help reduce viral load and shedding and hasten recovery, especially in seriously ill infants and children and those who are immunocompromised [12]. Additionally, there is growing interest in the use of oral ribavirin for the treatment of RSV and other respiratory viral illnesses in immunocompromised hosts; however, this is still under investigation [13].

The transmission of RSV is person-to-person or through direct or close contact with contaminated respiratory secretions. It also may aerosolize via large particle droplets and has been detected through molecular techniques in the air surrounding RSV-infected patients [14], although droplet transmission is not felt to be as important a mode of transmission as contact transmission. It also can persist on environmental surfaces and hands. Healthcare-associated transmission from patient to healthcare worker often occurs via hand to nose or hand to eye self-inoculation after contact with contaminated secretions. Patients hospitalized with suspected or proven RSV infection should be cared for under standard and contact precautions (Table 14.1), using gown and gloves, and rigorous hand hygiene. Some centers, especially bone marrow transplant units, will also use enhanced isolation precautions, and add droplet precautions, with healthcare workers wearing surgical masks during patient encounters [15-17]. In a quasi-experimental study in a children's hospital, the use of contact and droplet precautions was associated with a $39 \%$ reduction in nosocomial respiratory viral infections (including RSV) [1]. The use of eye goggles or face masks is not routinely recommended to reduce nosocomial transmission of RSV from patient to healthcare worker. Additional measures found to be helpful in some centers to minimize nosocomial spread of RSV include cohorting infants with suspected or proven RSV infection and excluding visitors with respiratory tract infections.

\section{Parainfluenza Viruses}

Parainfluenza viruses types 1, 2, 3, and 4 (PIVs) are enveloped RNA viruses belonging to the family Paramyxoviridae. They are common and an important cause of upper respiratory infections, as well as lower tract respiratory infections, such as laryngotracheobronchitis (croup), bronchiolitis, and pneumonia. The PIVs are also seasonal viruses, and usually circulate in early fall and late spring/early summer, with different serotypes having distinct seasonal patterns. Most children are infected with PIVs prior to 5 years of age. Infection with PIVs is usually self-limited; however, prolonged viral shedding, often associated with severe lower respiratory tract disease which may be fatal, may occur in immunocompromised patients. In children who have received bone marrow transplants, PIV infections commonly result in serious lower respiratory tract infections, especially if they occur before 


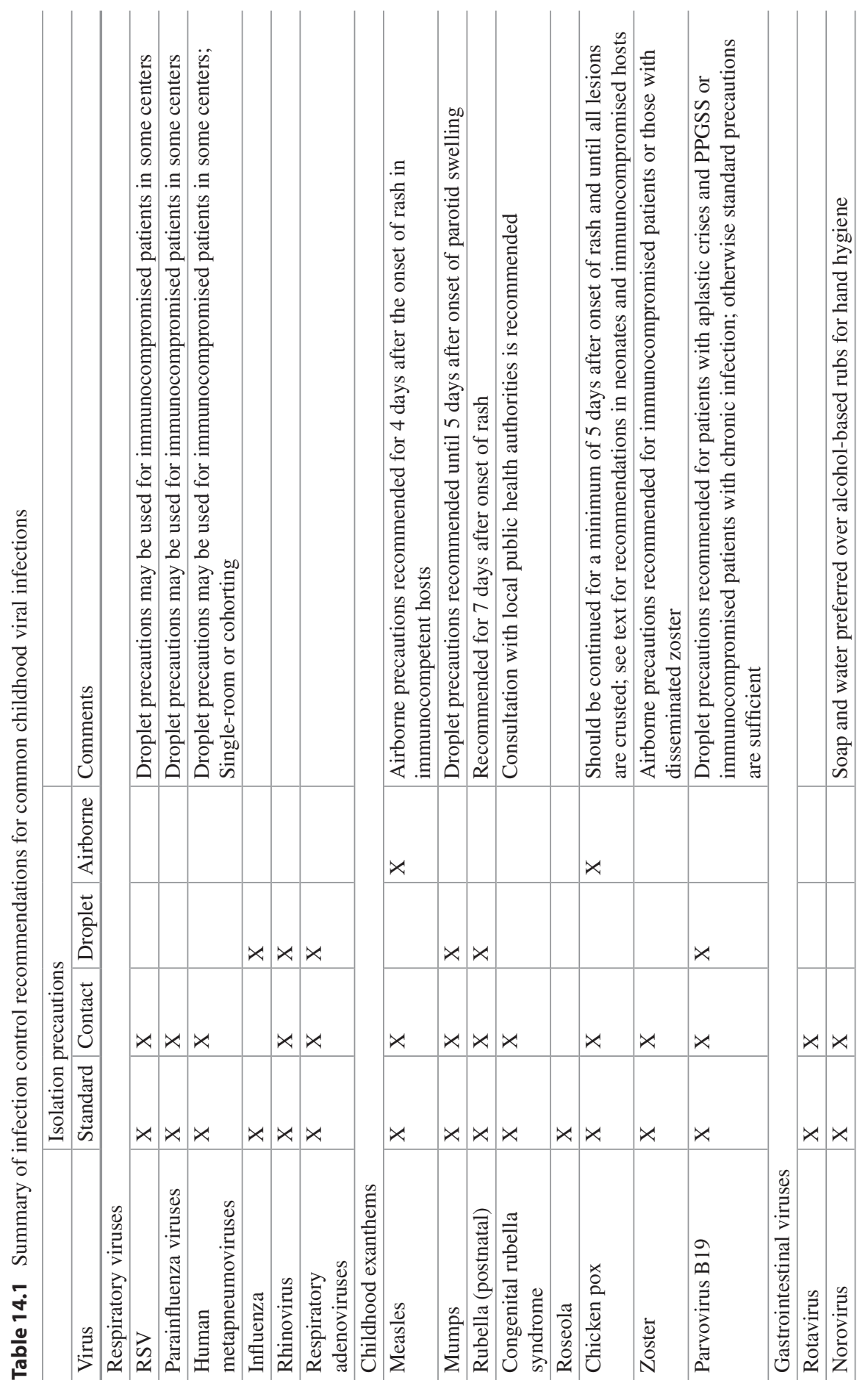




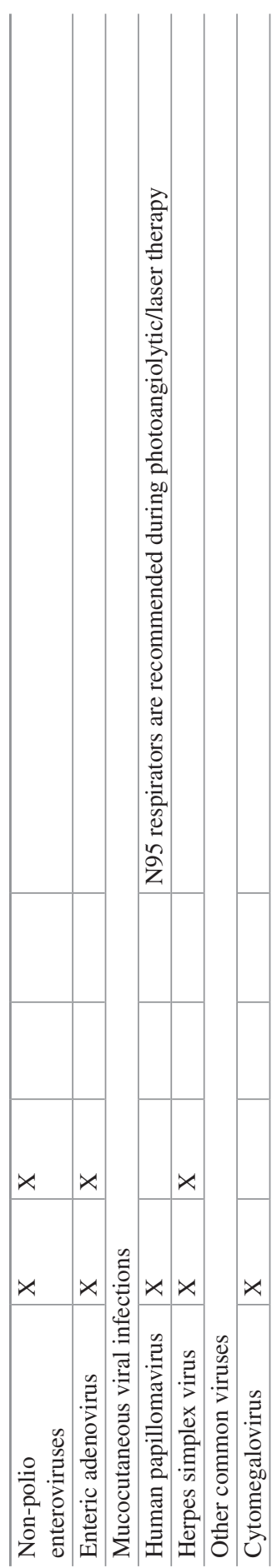


engraftment [18]. In such patients, ribavirin may be administered in efforts to shorten the duration and lessen the severity of disease [19].

Diagnosis of PIV infection can be suspected with reasonable certainty if a pediatric patient presents with a croup-like illness during the appropriate seasonal time period. It can be confirmed using traditional viral culture, direct immunofluorescence, or utilizing molecular diagnostics available in larger hospitals and reference laboratories.

Parainfluenza viruses are transmitted from person to person, primarily by direct contact with infected secretions, and also by droplet spread, when an infected person coughs or sneezes. Environmental surfaces may also harbor PIVs for several hours. Patients admitted to the hospital with croup or a suspected or proven PIV infection should be isolated under contact precautions, although some centers will also use droplet precautions.

\section{Human Metapneumovirus}

Human metapneumovirus (HMPV) was discovered in 2001 and is an enveloped, RNA, paramyxovirus. It causes acute respiratory tract illnesses in all ages. Most HMPV infections occur during late winter or early spring. Hospital outbreaks of HMPV have been reported and may have fatal consequences in patients with malignancies or who are immunocompromised from transplants [20, 21].

Diagnosis of HMPVs may be suspected in children presenting with upper or lower respiratory tract symptoms during late winter or early spring; however, it may mimic RSV or PIV infection, making precise clinical diagnosis with any certainty difficult. Therefore, HMPV infection is usually diagnosed definitively by viral respiratory panels utilizing molecular diagnostic techniques. Direct immunofluorescence may also be used to detect HMPV antigens in infected respiratory secretions.

Transmission of HMPVs is from person to person via contact with infected secretions, close personal contact, and from objects and surfaces that have been in contact with infected secretions. Contact precautions are recommended for patients hospitalized with suspected or proven HMPV infection. Some centers, especially bone marrow transplant units, will also add droplet precautions as described above.

\section{Influenza Viruses}

Influenza is caused by influenza A, B, or C virus, which are RNA viruses in the orthomyxovirus family. Influenza A virus can be further classified into subtypes based on two surface antigens (hemagglutinin (HA) and neuraminidase (NA)) and subtyped even further by the type of HA and NA (e.g., influenza A H1N1 or H3N2). Most infections with influenza virus in the Northern Hemisphere occur during the late fall and throughout winter into early spring, but there are annual and regional 
differences to the start and finish of each influenza season around the world. Pandemics with new and novel influenza viruses may also occur with periodicity of approximately every 20-30 years, most recently during the 2009 influenza A H1N1 pandemic. This then novel influenza A virus appeared to have enhanced transmissibility compared to previous seasonal influenza viruses, resulting in large numbers of patients presenting for medical treatment, a large number of critically ill patients requiring hospitalization for prolonged periods of time, and subsequently greater nosocomial transmission risk [22-27]. This particular influenza season was also associated with a large number of healthcare workers becoming ill, with up to $40 \%$ experiencing an influenza like illness (ILI) [28].

Influenza virus causes a febrile respiratory illness associated with fever, chills, malaise, myalgia, and cough in all age groups. Pediatric patients also commonly have vomiting and diarrhea. Newborns may present with apnea. Some children present with acute myositis, myocarditis, a sepsis-like syndrome, or neurological disease. Secondary bacterial pneumonia with Staphylococcus aureus, Streptococcus pyogenes, or S. pneumoniae can occur after influenza, sometimes resulting in serious, life-threatening disease.

Treatment of influenza virus infection and disease includes a variety of available antiviral medications, such as oseltamivir, peramivir, and zanamivir for influenza A and B virus infections. Influenza A and B viruses are also susceptible to inhaled ribavirin. Influenza B is never susceptible to amantadine or rimantadine; currently circulating influenza A virus subtypes are also not susceptible to amantadine/rimantadine, limiting the utility of these agents

In addition to standard precautions with strict hand hygiene procedures, droplet precautions are recommended for children hospitalized with influenza. Many hospitals will enforce droplet precautions at the time of admission, for all patients presenting with ILI, until the cause can be established through appropriate diagnostic testing. During the 2009 influenza A (H1N1) pandemic, infection control recommendations from the Centers for Disease Control and Prevention included the use of N95 respirators for healthcare workers caring for patients with suspected pandemic influenza, in addition to contact and droplet precautions. Realistically, however, many institutions had difficulty complying with these enhanced isolation precautions, either due to unavailability of N95 respirators, poor tolerability, work flow concerns, or patient volume, among other reasons. In addition, to their impact on individual patient symptoms, antiviral agents have a role in the prevention of spread of influenza within a hospital unit. Prompt antiviral therapy with oseltamivir or zanamivir for children hospitalized with ILI or confirmed influenza virus infections has been shown to reduce nosocomial spread of influenza by reducing viral shedding in infected patients [24]. Oseltamivir resistance may emerge during prolonged antiviral treatment of hospitalized immunocompromised hosts who have persistent and prolonged viral shedding while receiving antiviral therapy. Routine immunization of all healthcare workers with the seasonal influenza vaccine, prior to the beginning of the influenza season, is also recommended (and even mandatory in many hospitals) to reduce healthcare worker-to-patient transmission of infection. 


\section{Rhinoviruses and Respiratory Enteroviruses}

Rhinoviruses and the respiratory enteroviruses are small, non-enveloped, RNA, picornaviruses with over 100 serotypes. They are very common causes of upper respiratory tract infections, such as the "common cold," pharyngitis, and lower respiratory tract infections, such as bronchiolitis and pneumonia. Rhinoviruses also may exacerbate acute asthma. Most infections are mild and self-limited; however, severe and even fatal respiratory infections in premature infants and in immunocompromised hosts have been linked to rhinovirus and enterovirus infections [2931]. Patients with hypogammaglobulinemia may be particularly susceptible to persistent or severe infections. Rhinoviruses may occur year round and in all parts of the world. Nosocomial outbreaks of rhinovirus infection and disease in pediatric hospitals and neonatal intensive care units have been documented. A notable emerging pathogen included in this group is Enterovirus D68 (EV-D68); EV-D68 can cause respiratory illness or asthma exacerbation in children, as well as acute flaccid paralysis similar to poliomyelitis [32].

Transmission of rhinoviruses is predominantly person-to-person through prolonged and close contact with infected secretions, with subsequent autoinoculation by touching hands to the face, eyes, mouth, or nose. However, there is also experimental evidence to support indirect contact with contaminated fomites and surfaces as modes of transmission [33], as well as large droplet contact transmission. Nosocomial outbreaks of rhinovirus infection have been documented, especially in preterm infants hospitalized in neonatal intensive care units [30]. Patients in the healthcare setting with suspected or proven rhinovirus or respiratory enterovirus infections should be cared for under standard, contact, and droplet precautions. Rigorous hand hygiene should also be encouraged.

\section{Respiratory Adenoviruses}

Adenoviruses (ADV) are non-enveloped, DNA viruses with over 50 distinct serotypes. Some adenoviruses are associated primarily with respiratory tract disease (usually serotypes $1-5,7,14$ [recently shown to be a potentially severe, fatal serotype], and 21). The respiratory adenoviruses infect pediatric patients of all ages. They may cause upper respiratory tract disease, such as rhinorrhea, pharyngitis, exudative tonsillitis, a pertussis-like syndrome, conjunctivitis, and epidemic keratoconjunctivitis, as well as lower respiratory tract disease, such as croup, bronchiolitis, and pneumonia. They do not appear to have a distinct seasonality and may occur in all seasons of the year. Most infections are self-limited in healthy hosts, but severe and fatal disease may occur in newborns and the immunocompromised.

Transmission of ADV in the healthcare setting is primarily through person-toperson spread via contact with infected secretions, as well as by fomites, contaminated environmental surfaces (where ADV may remain for extended periods of time due to their non-enveloped nature), and by droplet spread. In one study, $37 \%$ of environmental samples taken from a children's hospital waiting room in the winter had evidence of 
adenovirus [7], highlighting the potential for this virus to persist in the environment. Nosocomial outbreaks in pediatric wards, bone marrow transplant units, intensive care units, ophthalmology clinics, and neonatal intensive care units have been documented $[34,35]$. Medical devices, such as eye specula (blepharostat) used to examine the eyes of newborns and preterm infants at risk for retinopathy of prematurity in the nurseries and neonatal intensive care units, have also been linked to nosocomial outbreaks [34]. In addition, tonometer prisms used in ophthalmology clinics may be a source of ADV infection after eye exams [36]. Given this notable risk of infection transmission, singleuse eye specula and tonometers are preferred if available. Autoclave sterilization is the preferred method of sterilization of reusable eyelid specula between neonate examinations. However, if autoclave use is not available or will damage the instrument, washing the specula with chlorhexidine gluconate or dilute bleach (sodium hypochlorite) in between examinations may be more effective than cleaning with an alcohol swab [3739]. Patients in the healthcare setting with suspected or proven ADV infections should be cared for under standard, contact, and droplet precautions. In addition, rigorous hand hygiene with soap and water or an alcohol-based hand rub should be enforced and environmental surfaces should be disinfected frequently [40]. Notably, one laboratorybased study found that alcohol-based solutions in hand sanitizers may not be effective against some strains of adenovirus [36].

Treatment of routine ADV infections is supportive, as most infections are selflimited. Severe, life-threatening adenovirus infections in immunocompromised hosts or newborns have been treated with cidofovir or brincidofovir.

\section{Mimiviruses}

Mimiviruses ("mimicking microbes") are the largest known DNA viruses and are considered an emerging cause of pneumonia [41-43]. They are a member of the Mimiviridae order, Mimiviridae family of nucleocytoplasmic large DNA viruses, and Mimivirus genus, and can be found within the amoeba, Acanthamoeba polyphaga. They were originally discovered in amoeba in 1992 and were thought to be bacteria, but in 2003 they were confirmed to be giant viruses. They can be cultured using special isolation techniques involving amoebae as a eukaryotic co-host and detected by molecular techniques. Clinical diagnosis, however, remains a challenge since they are difficult to detect. However, serologic assays have suggested these viruses may play a role in community-acquired and healthcare-associated pneumonia in adults [44]. Knowledge of their role, if any, in healthcare-associated, pediatric pneumonia is evolving.

\section{Childhood Viral Diseases and Exanthems}

The childhood viral diseases and exanthems may contribute to healthcare viral infections though transmission in the hospital and include measles, mumps, rubella, roseola, varicella (or chicken pox), and parvovirus B19. Measles and chicken pox 
are considered among the most highly contagious infectious diseases and therefore pose a significant risk for nosocomial transmission.

\section{Measles (Rubeola)}

Measles, or rubeola, is a highly contagious febrile childhood exanthem, characterized by cough, coryza, and conjunctivitis. Complications such as otitis media, pneumonia, and meningoencephalitis also may occur. Fatalities may occur in immunocompromised hosts and patients who develop subacute sclerosing panencephalitis.

Measles is caused by the measles virus, an RNA paramyxovirus. Measles is transmitted person-to-person through direct contact with infected secretions or via droplet or airborne spread. Measles is considered one of the most highly contagious infectious diseases with an average of 12-18 secondary cases in a susceptible population following exposure to a primary case; however, variability exists in the exact degree of contagion depending on the specific population studied [45, 46]. Healthcare-associated transmission of measles is well documented [47, 48]. The pediatric emergency room has been reported as a particularly common healthcare venue for measles exposure and transmission [49]. Measles transmission in the healthcare setting has involved both patients and healthcare workers. Patients with suspected or proven measles admitted to the hospital or seen in clinics or emergency centers should be cared for under standard and airborne precautions. In addition, patients exposed to measles in the hospital should be placed on airborne precautions from day 5 to day 21 after the exposure and maintained in airborne precautions if they develop measles illness and require continued hospitalization. Postexposure immunoprophylaxis in nonimmune individuals through measles vaccine is effective if given within $72 \mathrm{~h}$ of exposure and through immune globulin if given within 6 days of exposure [50]. Healthcare workers should be immunized against measles or provide serologic evidence of immunity prior to caring for patients.

Diagnosis of measles can be suspected clinically in children exhibiting the classic signs and symptoms and confirmed by detection of measles IgM antibody in serum if obtained at least $72 \mathrm{~h}$ after the onset of the measles rash. Measles virus may also detected by viral culture and molecular assays, performed in reference or public health laboratories.

Treatment of measles is primarily supportive. The World Health Organization (WHO) recommends vitamin A treatment for all children, in all countries, diagnosed with measles. Ribavirin has been administered to severely ill, immunocompromised patients with measles with variable success.

\section{Mumps}

Mumps (epidemic parotitis) is a febrile, childhood respiratory disease uniquely characterized by parotitis and orchitis. Meningoencephalitis, myocarditis, and other systemic manifestations may also occur. 
Mumps is caused by the mumps virus, an RNA paramyxovirus, and is a vaccinepreventable illness. Mumps occurs all over the world, and community outbreaks occur, even in areas where immunization is routine. Healthcare-associated transmission of mumps has also occasionally been reported [51-53]. The virus is spread by contact with infected saliva and respiratory secretions. Patients hospitalized with suspected or proven mumps should be isolated under standard and droplet precautions until 5 days after onset of parotitis. Healthcare workers should be immunized against mumps or provide serologic evidence of immunity prior to performing patient care duties

\section{Rubella}

Rubella is a febrile childhood exanthem, with a generalized erythematous maculopapular rash and lymphadenopathy. It is caused by the RNA virus, rubella virus, a member of the Togaviridae family. Rubella virus also causes congenital rubella syndrome (CRS) in congenitally infected infants, which is associated with intrauterine growth restriction, petechiae, hepatosplenomegaly, microcephaly, eye findings (cataracts, pigmentary retinopathy, glaucoma), cardiac disease (patent ductus arteriosus), sensorineural hearing loss, and neurologic abnormalities [5].

Rubella and thus CRS are vaccine-preventable diseases in most developed countries. However, there are still resource-limited areas where rubella immunization is not routine and rubella/CRS occurs. Therefore, healthcare professionals should be vigilant about suspecting CRS in infants from resource-limited countries, especially if they present with one or more clinical symptoms associated with CRS.

Rubella and CRS may be diagnosed by serologic detection of rubella IgM. Isolation of rubella virus in cell culture and detection of rubella virus by molecular diagnostic techniques may also be done in specialized public health laboratories, such as the Centers for Disease Control and Prevention (CDC).

Patients admitted to the hospital or cared for in the outpatient setting with suspected or proven rubella should be cared for under standard and droplet precautions [50]. Infants with CRS should be cared for in the hospital and outpatient setting under contact precautions, until they are 1 year of age or until two samples of clinical specimens (saliva/throat and urine) obtained at least 1 month apart are negative for rubella virus in tests performed by a reliable public health laboratory.

\section{Varicella Zoster Virus Infections (Chicken Pox and Zoster)}

Varicella zoster virus (VZV) is a DNA herpesvirus and the cause of chicken pox, a highly contagious, febrile, papulovesicular childhood exanthem, and zoster (shingles), a localized dermatomal papulovesicular reactivation. Infection with VZV may be associated with severe infections, such as pneumonia, hepatitis with hepatic necrosis, encephalitis, or hemorrhagic varicella in immunocompromised children. Chicken pox and zoster are vaccine-preventable diseases, with currently no clear 
seasonable distribution in countries where routine vaccination is recommended. In countries without routine immunization, a late winter-early spring seasonal distribution may be observed.

Infection with VZV, in both normal and immunocompromised hosts, is commonly treated with antivirals, such as acyclovir and valacyclovir; antivirals are not typically required in otherwise healthy children given the self-limited nature of the illness. Consideration should be given to the treatment of VZV in immunocompetent children $>12$-years old, those with chronic pulmonary or skin disorders, and those taking salicylates or corticosteroids [50]. Intravenous acyclovir is recommended for immunocompromised patients. Other antivirals commonly used to treat cytomegalovirus (CMV), such as ganciclovir, valganciclovir, foscarnet, and cidofovir, also have activity against VZV. Administration of varicella immune globulin (VariZIG) or intravenous immune globulin (IVIG) may be used in select situations for postexposure immunoprophylaxis, in addition to antiviral therapy with acyclovir or valacyclovir [50].

Transmission of VZV is person-to-person through the airborne route and from direct contact with patients with VZV infection. Skin lesions from chicken pox and zoster contain high titers of infectious virus which may aerosolize or be deposited on fomites or surfaces and are the most likely sources of viral transmission. Molecular techniques have also detected VZV DNA in the air surrounding patients with varicella zoster infections (chicken pox and zoster) [54]. Transmission from respiratory droplets is thought to be much less common. Nosocomial transmission of VZV infections is well documented in the healthcare setting (especially pediatric wards), and healthcare-associated outbreaks, sometimes with fatal outcomes in immunocompromised hosts, may occur $[55,56]$. Patients hospitalized with chicken pox or disseminated zoster (or immunocompromised patients with simple zoster who may be at risk for dissemination) should be isolated in a private room equipped with a separate exhaust system and negative pressure air relative to the hallway, if such rooms are available [50]. They should also, in addition to standard precautions, be cared for with contact and airborne precautions. Isolation should continue until no new lesions occur, and all lesions that have occurred are completely crusted over. In addition, nonimmune patients in the hospital setting who have been exposed to varicella should also be isolated under airborne and contact precautions for 8-21 days after exposure (and up to 28 days after exposure if VariZIG or IVIG were received as postexposure immunoprophylaxis) if they require ongoing hospitalization. Newborns born to mothers with varicella at the time of delivery should also be isolated and cared for under contact and airborne precautions while hospitalized (or until 21 days of age or 28 days if immunoglobulin is provided). Normal patients with localized zoster may not require special isolation with airborne and contact precautions if the zoster lesions are able to be completely covered. However, some hospital infection control officers may prefer to isolate even immunocompetent patients with localized zoster under airborne precautions and, if available, place them in a negative pressure room, especially if they are roomed near immunocompromised patients.

Healthcare workers should provide documentation of either immunization with two doses of varicella vaccine or immunity to varicella zoster virus infection 
(through serologic testing for the presence of VZV IgG from a previous infection) prior to assuming patient care responsibilities.

\section{Parvovirus}

Parvovirus B19 is a common, single-stranded DNA virus that causes erythema infectiosum or fifth disease in normal healthy children. It also may cause a polyarthropathy syndrome or papular purpuric gloves and socks syndrome (PPGSS). Chronic anemia and red cell aplasia may occur in immunocompromised hosts, and transient aplastic crisis in patients with sickle cell anemia accompanied by prolonged viral excretion; such severe manifestations are potentially contagious in the healthcare setting. Newborns may also present with hydrops fetalis or congenital anemia. Nosocomial transmission of parvovirus B19 infections can occur from person to person through droplet transmission and, rarely, through blood products [57]. Healthcare-associated outbreaks of parvovirus B19 affecting both patients and hospital personnel have been described [58].

Detection of parvovirus B19 infection is by serologic assays of virus-specific $\operatorname{IgG}$ and IgM and detection of viral DNA using molecular techniques. Most blood products used for transfusion do not contain parvovirus B19, and when they do, it is often present only at a very low level. Blood product transmission of parvovirus B19 rarely results in symptomatic illness [57].

Patients hospitalized with parvovirus B19 infections who have aplastic crises, PPGSS, or chronic infection, should be isolated with standard and droplet precautions, because they often shed virus in larger quantities for extended periods of time and are therefore potentially contagious in the healthcare setting. Pregnant healthcare providers should be informed about the risks for exposure to parvovirus B19 and strategies to mitigate this risk (i.e., strict adherence to infection control policies).

\section{Gastrointestinal Viruses}

The gastrointestinal viruses are a major cause of healthcare-associated viral infections, and the viruses of major nosocomial importance include rotavirus, caliciviruses (including norovirus), astrovirus, toroviruses, enteric adenoviruses (especially serotypes 40/41), enteric enteroviruses, parechoviruses, and hepatitis A virus. The treatment of such infections is largely supportive with fluid and electrolyte replacement as needed.

\section{Rotavirus}

Rotavirus is an RNA virus and is a common cause of febrile diarrhea in young infants, often resulting in dehydration and electrolyte and acid-base abnormalities. It is usually a seasonal virus, with peak transmission occurring in fall and 
winter. Rotavirus commonly infects young infants who are in diapers, is often shed in large quantities in the stool even for many days after diarrhea has resolved, and survives for long periods of time on environmental surfaces. These specific characteristics allow for the ready nosocomial spread of rotavirus. Since the advent of the rotavirus vaccine, the epidemiology of rotavirus diarrhea has changed in developed countries who employ routine immunization, with a substantial decrease in outpatient visits and hospitalizations for rotavirus diarrhea as well as reduced nosocomial acquisition of infection [59]. Rotavirus is discussed in more detail in Chap. 12.

\section{Caliciviruses, Including Norovirus}

Caliciviruses, including norovirus, are a diverse group of RNA viruses that cause a self-limited gastrointestinal illness characterized by nausea, vomiting, and crampy abdominal pain with diarrhea. In premature infants, as well as immunocompromised or medically fragile patients, norovirus can be a severe, protracted and even fatal diarrheal illness [60]. Norovirus also has been associated with necrotizing enterocolitis in neonatal intensive care units [61]. Since the advent of routine immunization with rotavirus vaccine, norovirus has now become a leading cause of gastroenteritis in the United States and other developed countries, and an important nosocomial viral pathogen. Norovirus is discussed in more detail in Chap. 12.

\section{Non-polio Gastrointestinal Enteroviruses and Parechoviruses}

The non-polio enteroviruses are small RNA viruses and include coxsackie viruses groups $\mathrm{A}$ and $\mathrm{B}$, echoviruses, and a variety of other enteroviruses, comprising over 100 serotypes. Enteroviruses also are classified genetically as belonging to groups $\mathrm{A}, \mathrm{B}, \mathrm{C}$, or $\mathrm{D}$, while still retaining serotype designations. The parechoviruses were formerly known as echoviruses 22 and 23 . These viruses are common and distributed worldwide, with a summer and fall seasonal pattern in most countries.

The non-polio enteroviruses and parechoviruses cause vomiting and diarrhea, hepatitis, hand-foot-mouth disease, and severe disease with an acute viral sepsis syndrome. An exanthem, myocarditis, and meningoencephalitis may also occur in neonates and immunocompromised patients, including transplant recipients, children with cancer, and those with hypogammaglobulinemia. Outbreaks of enterovirus and parechovirus infections, often with severe disease, have been documented in pediatric hospitals, especially neonatal intensive care units [62-65].

Patients with suspected or documented infections with enteroviruses or parechovirus should be under both standard and contact precautions. In nursery outbreaks, 
cohorting may be helpful to limit spread of the virus. Vigorous hand hygiene and decontamination of environmental surfaces are also recommended.

\section{Enteric Adenoviruses}

Many adenoviruses may cause gastrointestinal disease, but the serotypes 40/41 as well as serotypes $12,18,31,52$, and 61 are associated primarily with diarrhea. Most infections are self-limited in healthy hosts, but severe and fatal disease may occur in newborns and immunocompromised hosts [66].

Transmission of ADV in the healthcare setting is primarily person-to-person through contact with infected secretions, as well as by fomites, infected environmental surfaces, and by droplet spread. Nosocomial outbreaks in pediatric wards, intensive care units, and neonatal intensive care units have been documented [67]. All patients hospitalized with a suspected or proven gastrointestinal virus should be isolated under standard and contact precautions for duration of illness.

As discussed above, the treatment of routine ADV infections is supportive, as most infections are self-limited; severe infections in immunocompromised hosts may be managed with cidofovir or brincidofovir.

\section{Mucocutaneous Viruses}

\section{Human Papillomaviruses}

The human papillomaviruses (HPV) are DNA viruses which can be grouped by their ability to infect cutaneous or mucosal sites and their capacity (defined as high or low risk) to cause cancer. The HPVs of nosocomial transmission interest are primarily those low risk, cutaneous types 6 and 11, which cause oral or cutaneous warts, laryngeal papillomas, and juvenile respiratory papillomatosis. The latter is a chronic disease of the respiratory tract that often requires repeated surgical procedures or photoangiolytic laser treatments to alleviate long-term stenotic complications in the airways. Oral warts and oropharyngeal cancers caused by HPV types 16 and 18 also may require laser/electrosurgery procedures. These procedures may generate laser plumes, aerosols, or smoke that may contain HPV virus particles and therefore are a potential risk for healthcare workers. The risk of inhalation of potentially infectious aerosols that may be generated during the procedure can be mitigated by performing the procedures in a well-ventilated room, while using localized smoke evacuator exhaust ventilation, and wearing of N95 respirators during the procedure [68]. Reports also exist of HPV contamination of improperly sterilized gynecologic instruments and vaginal ultrasound probes [69, 70]. Patients with HPV infections, however, do not require special precautions during normal, routine medical encounters that are not associated with laser therapy. 


\section{Herpes Simplex Viruses}

The herpes simplex viruses (HSV) types 1 and 2 are enveloped DNA viruses which commonly cause asymptomatic infections, as well as a variety of illnesses, including the following: neonatal HSV syndromes; skin, oral, and/or genital lesions; eczema herpeticum; keratoconjunctivitis; acute retinal necrosis; and disseminated disease, which may have a fatal outcome. Patients who are critically ill and intubated, have extensive burns, or are immunocompromised may experience a reactivation of HSV infection and may develop oropharyngeal or cutaneous herpetic lesions. As such, it is not uncommon for patients to experience HSV reactivation and recurrent disease while in the hospital. Alternatively, physiologic stress may induce laboratory detectable HSV reactivation without overt disease [71]. Up to $14 \%$ of patients with septic shock develop HSV reactivation with transient viremia, although the clinical significance of this is a bit unclear [72, 73]. Primary corneal graft failure has also been reported due to reactivation of latent corneal HSV in donor tissue following corneal transplantation [74]. Nosocomial outbreaks with HSV have been reported in eye clinics.

Antiviral treatment with acyclovir or valacyclovir is commonly used for active HSV disease, suppression of HSV infection after successful treatment, or prevention of reactivation HSV infection. The antivirals ganciclovir, valganciclovir, foscarnet, and cidofovir also have activity against HSV and are second-line antivirals for HSV treatment.

In addition to standard precautions, patients with HSV mucocutaneous or skin lesions should be placed on contact precautions. However if the HSV recurrence consists of a single lesion or small, localized lesions, standard precautions may be appropriate, with good hand hygiene technique. Single use eye instruments are preferred for routine eye exams and exams in neonates for retinopathy or prematurity. Sodium hypochlorite (dilute bleach) appears to effectively disinfect HSV on reusable tonometers and specula used for eye exams. In some studies $70 \%$ isopropyl alcohol was also an effective disinfectant against HSV on eye specula $[37,38,75]$.

\section{Blood-Borne and Tissue-Borne Viruses}

Viruses that may be found in, and potentially transmitted by, blood product or tissue or organ donation include hepatitis B, hepatitis $\mathrm{C}$, hepatitis E, cytomegalovirus (CMV), human herpes virus 8, parvovirus B19, HIV, HTLV-1 and HTLV2 , dengue virus, West Nile virus, and Colorado tick fever virus. In addition, prions may also be potentially transmitted in this manner. Of these, CMV is the most commonly transmitted through blood products in the United States [76]. Since an in-depth discussion on blood-borne pathogens is beyond the scope of this chapter, the reader seeking more details on blood product screening and safety and the management of these infections is asked to see reviews on potential transfusion-transmitted viruses $[4,50]$. 


\section{Breast Milk-Borne Infections}

A variety of viruses may be detected and potentially transmitted through maternal breast milk, including CMV, hepatitis B, hepatitis C, HIV, HTLV-1 and HTLV-2, herpes simplex virus, rubella, varicella, and West Nile virus. Of these, CMV has the most relevance as a healthcare-associated virus [50]. Additional discussion of this topic is provided in Chap. 15.

\section{Cytomegalovirus}

CMV is a common herpes family DNA virus that most commonly causes asymptomatic infection but also may cause mononucleosis syndrome, hepatitis, pneumonitis, or a viral sepsis-like syndrome in premature infants. It can be transmitted via breast milk, blood product transfusions, and tissue or organ donation. Person-toperson transmission of CMV has not been documented to occur in the hospital setting, even though CMV transmission is common in the family and daycare settings, where close contact and the sharing of food, drink, and toys are common. CMV infections may also reactivate in immunocompromised patients, such as transplant recipients, burn patients, or patients in intensive care units, and cause serious disease $[77,78]$.

Postnatal CMV infection in the very low birth weight infant is an important healthcare-associated viral infection in the neonatal intensive care unit. Primary sources for postnatal CMV infection in these vulnerable neonates include blood transfusions and breast milk. Most neonatal intensive care units provide CMVseronegative or CMV-“safe," leukocyte-depleted sources of blood products, reducing the risk of blood product transmission considerably. Recent studies have shown that maternal breast milk is a primary source of postnatal CMV infection and disease in preterm infants [79]. Fresh or refrigerated breast milk is more likely to transmit CMV than frozen-thawed breast milk, and pasteurized breast milk carries very little to nil risk of CMV transmission [79-81].

Infants with postnatal CMV infection from breast milk feedings typically become ill after the first month of life and may present with apnea and bradycardia, thrombocytopenia, neutropenia, hepatitis, viral sepsis syndrome, necrotizing enterocolitis, or pneumonitis. Postnatal CMV infection is best documented by a negative CMV urine or saliva culture or molecular detection test performed in the first 21 days of life (to exclude congenital CMV), followed by a subsequent positive CMV detection test on the same samples after 1 month of life. These infants are often viremic and CMV can be detected and quantified in blood by molecular techniques. Since severe illness and even death may occur in postnatal CMV infections in very low birth weight infants, antiviral therapy with ganciclovir or valganciclovir may be indicated in infants who present with serious symptoms and/or demonstrate significant viremia. Antiviral treatment is often administered for 3-6 weeks, depending on clinical and virologic response.

Infants with postnatal CMV infection do not require special isolation procedures and standard precautions are recommended. 


\section{Viruses that Require Special Containment and Special Circumstances}

Recent worldwide outbreaks of emerging/re-emerging highly virulent viral infections have highlighted the importance of continued vigilance in infection control and prevention in an increasingly "global world." The following section will highlight infection control considerations for highly virulent viral pathogens.

\section{Severe Acute Respiratory Syndrome Coronavirus (SARS-CoV) and Middle East Respiratory Syndrome Coronavirus (MERS-CoV)}

The severe acute respiratory syndromes (SARS) include SARS-coronavirus (CoV) and Middle East respiratory syndrome coronavirus (MERS-CoV) [82, 83]. These syndromes are acute viral respiratory and gastrointestinal illnesses caused by novel coronaviruses and are spread from person to person through close contact. MERS$\mathrm{CoV}$ may also be transmitted through contact with infected camels. Infection with SARS-CoV was first reported in Asia in 2003 and becomes a global epidemic, affecting over 20 countries in North and South America, Europe, and Asia. Since 2004, there have been no reported cases of SARS-CoV anywhere in the world. Infection with MERS-CoV was first reported in Jordan and Saudi Arabia in 2012 and has spread in the Arabian Peninsula and to the Republic of Korea. The WHO and CDC monitor SARS-CoV and MERS-CoV activity globally.

Both SARS-CoV and MERS-CoV infections in children can be suspected if patients have had contact with a known case of SARS-CoV (hypothetically) or MERS-CoV, recent travel to areas of the world with active SARS-CoV or MERS$\mathrm{CoV}$ transmission, or close contact with someone ill who had such travel. Usually infants and young children have milder illness, such as fever, rhinorrhea, and slight cough. However, older children and adolescents may have severe illness with fever, cough rhinorrhea, headache, chills, lymphopenia, dyspnea, hypoxemia, and/or respiratory failure requiring mechanical ventilation. Unilateral or bilateral pneumonia on chest radiographs also are typically present in severe illness. While the illness is primarily respiratory, diarrhea also may occur. Both SARS-CoV and MERS-CoV infections have a high reported mortality rate (a mortality rate ranging from $20 \%$ to $50 \%$ has been reported for MERS-CoV in some series) [84, 85]. There are no specific antiviral medications available proven to be effective against coronaviruses. Treatment is therefore primarily symptomatic, with fluid management and mechanical ventilation administered as needed.

Importantly, a number of cases of transmission of these viruses from patients or family members to other patients or hospital staff with serious consequences have been documented [86]. Given the potential severity of these illnesses, attention to appropriate isolation and infection control measures is essential. While most coronaviruses require only routine and contact precautions, patients suspected to have infection with (often referred to as a person under investigation or PUI) or proven to be infected with SARS-CoV or MERS-CoV require airborne, droplet, and contact 
precautions. Patients should be given a mask to wear over their nose and mouth and isolated in an airborne infection isolation room (AIIR) or a special isolation unit (SIU), if available. Only specially trained, essential personnel should enter the hospital room to care for the patient, and a log of all persons should be maintained, and their symptoms monitored for fever, cough, or other acute illnesses for 14 days after contact with the patient. Personnel should be trained in both standard hand hygiene and personal protective equipment (PPE), such as gloves, gowns, and eye protection, as well as use of fit-tested, N95 filtering facepiece respirators in AIIRs or powered air-purifying respirators (PAPRs) used in SIUs (Figs. 14.1 and 14.2) [82, 83]. Caution should be used when performing aerosol-generating procedures, such as suctioning, intubation, linen changing, and toilet flushing [87]. Patients suspected or proven to be infected with either SARS-CoV or MERS-CoV should be reported to the healthcare facility infection control officer and the local public health authorities immediately.

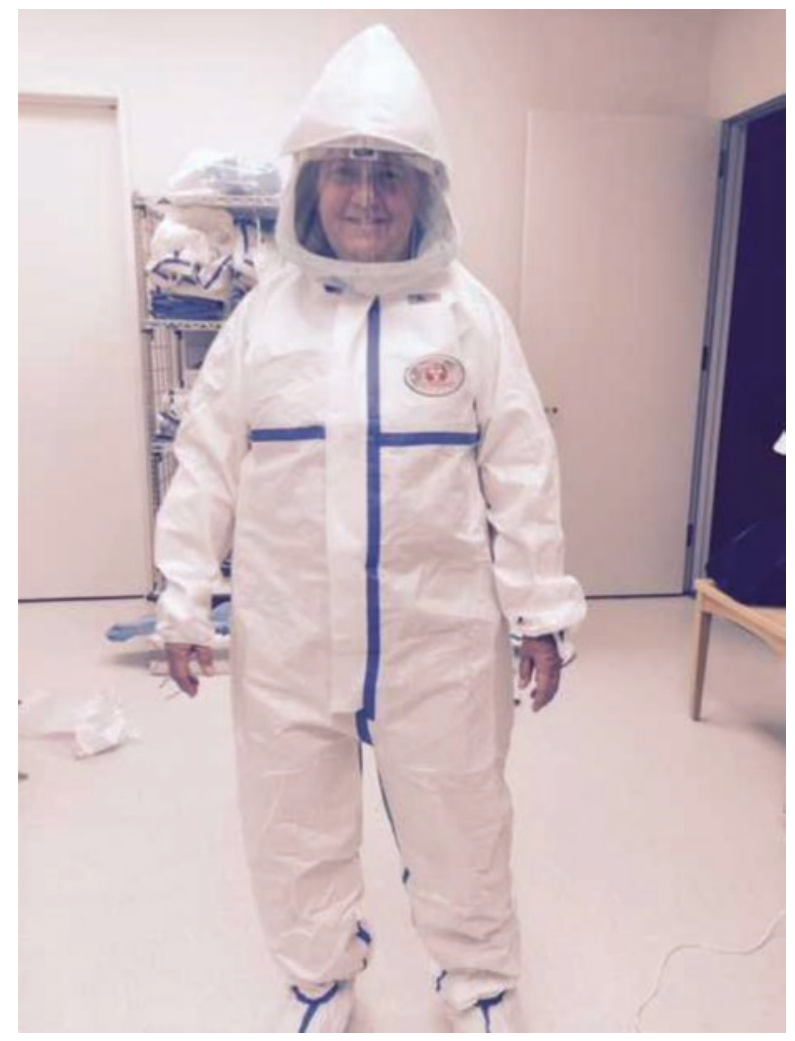

Fig. 14.1 The author, wearing special isolation unit (SIU) personal protective equipment (PPE) inner layer - consisting of a liquid impervious jump suit with powered air-purifying respirator (PAPR) 


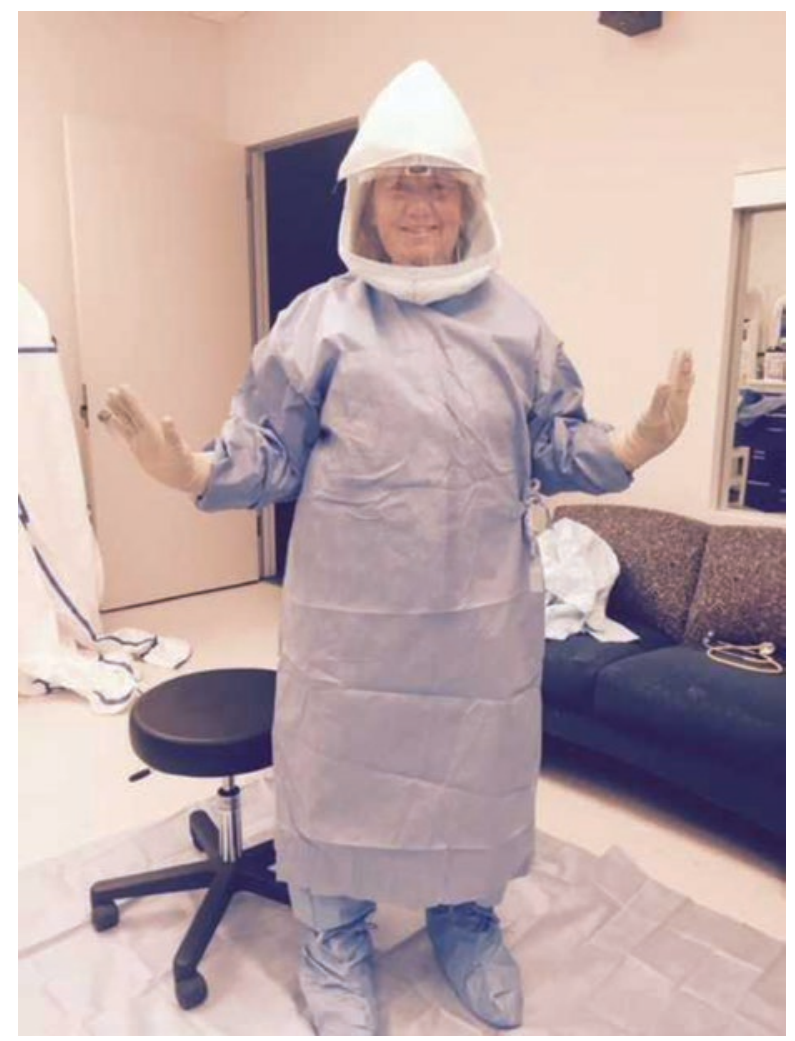

Fig. 14.2 The author, wearing special isolation unit (SIU) personal protective equipment (PPE) outer layer - consisting of liquid impervious gown, three layers of gloves, and boots, with powered air-purifying respirator (PAPR)

\section{Viral Hemorrhagic Fevers: Filoviruses (Ebola and Marburg), Bunyaviruses (Hemorrhagic Fever with Renal Syndrome (HFRS), Crimean-Congo Hemorrhagic Fever (CCHF) and Rift Valley Fever (RVF), Arenaviruses (Lassa Fever), and Flaviviruses (Dengue Fever)}

The viral hemorrhagic fevers (VHFs) are a group of illnesses caused by different families of viruses (filoviruses, bunyaviruses, arenaviruses, and flaviviruses) that cause a similar multisystem illness characterized by fever, vomiting and diarrhea, respiratory symptoms, as well as vascular damage, with disseminated intravascular coagulation and hemorrhage. These infections can be life threatening.

Dengue fever, caused by flaviviruses, is transmitted through mosquito vectors and is not transmitted through person-to-person contact (with the exception of rare cases of transfusion-associated transmission). Therefore standard precautions are usually recommended, since the healthcare-associated risks of this VHF is low. 
Similarly, the VHF caused by bunyaviruses (HFRS, CCHF, and RVF) require standard precautions, with the addition of contact, droplet, or airborne precautions for some cases of CCHF, with isolation in an AAIR or SIU required in certain circumstances which should be individualized. Consultation with public health authorities is recommended in suspected cases of CCHF.

Of the VHFs, Ebola virus disease (EVD) poses the greatest healthcare-associated transmission risk and therefore will be the focus of this section [88]. Ebola virus disease (EVD) is caused by infection with one of the five known Ebola viruses. Ebola virus was first discovered in 1976 near the Ebola River in the Democratic Republic of Congo. It has caused many severe outbreaks in Africa, and in 20142016, an Ebola virus outbreak in West Africa spread to urban areas in Africa. Subsequently, through commercial air travel, the outbreak became a global epidemic with spread to the United States and Europe and also involving infection in healthcare workers. Ebola virus transmission should always be considered to be potentially occurring in sub-Saharan Africa, and with global air travel common, the potential spread outside of Africa remains an ongoing concern for healthcare workers. The CDC and WHO constantly monitor EVD activity.

Ebola virus is spread from person to person through direct contact with bodily fluids or contaminated linens, trash, medical equipment, and instruments in contact with a person who is sick or who has died from EVD. Ebola virus may also be transmitted through needle sticks or sexual contact. Vertical transmission from mother to fetus/newborn has been documented. It is also been spread through direct contact with infected fruit bats or primates, especially if eaten as "bushmeat."

Ebola virus infection usually causes fever, headache, myalgias, and weakness early in the course of illness. It may mimic a flu-like illness. A rash is often present, and vomiting and diarrhea are common, as well. Respiratory symptoms may also occur, especially in children. Infection with Ebola virus should be suspected in patients with these symptoms who have had recent travel in an area where Ebola virus transmission is reported to be occurring; furthermore, such suspected cases should be reported to public health authorities at once. In the latter stages of the illness, disseminated intravascular coagulation occurs, followed by hemorrhage and death in up to $50 \%$ of patients. All bodily fluids should be considered to be highly infectious and handled with extreme care [88].

The diagnosis of Ebola virus can be established by detection of Ebola virus in the blood by PCR. The PCR test must be performed at first suspicion of EVD and also at least 3 days after the onset of febrile symptoms, at which time significant viremia may be present. Consultation with public health officials (such as the CDC) is highly recommended regarding the handling and processing of specimens from patients with suspected or proven EVD.

Treatment of EVD is primarily symptomatic, with fluid resuscitation and, if needed and determined to be medically beneficial on an individual basis, mechanical ventilation and other critical care support. Currently, there are no antiviral medications licensed for treatment of EVD. However, experimental antiviral clinical trial protocols are available. In addition, immunotherapeutics, using convalescent plasma or blood transfusions from EVD survivors, has been administered with some 
promise of benefit. Finally, a variety of monoclonal antibodies and vaccine strategies are under development or in clinical trials.

PUIs or those proven to be infected with Ebola virus should be given a mask to wear over their nose and mouth if they are coughing and not vomiting; isolated in an AIIR or SIU, if available; and transferred, if possible, to a designated Ebola treatment center for children, which is available in developed countries [88]. In resource-limited healthcare facilities, mobile Ebola treatment units (ETUs) are typically set up, with "cold zone" and "hot zone" designations to minimize the risk of healthcare-associated transmission between patients, from patients to healthcare workers, and to the community [88]. Only specially trained, essential personnel should enter the SIU, ETU, or hospital room to care for the patient with suspected or proven EVD, and a log of all persons should be maintained, and their symptoms monitored for fever, cough, or other acute illnesses for 14 days after contact with the patient. Personnel should be trained in both standard hand hygiene and PPE, such as gloves, gowns, and eye and face shield protection, as well as use of fittested, N95 filtering facepiece respirators and face shields in AIIRs or PAPRs used in SIUs [89]. Caution should be used when performing all aerosol-generating procedures. All procedures, such as blood drawing or central line access, should be minimized, carefully planned, and performed with extreme care. All trash contaminated with bodily fluids requires special handling and should be double-bagged, taped closed, and autoclaved or incinerated prior to leaving the SIU or ETU. Toilets should be flushed with the lid closed, or with a covering over the bowl during the flush, to minimize aerosols of potentially infectious material [87]. All surfaces in contact with the patient, or near the patient, should be frequently cleaned and decontaminated, and special handling is required after a spill or body fluid contamination. PUIs or those proven to be infected with Ebola virus should be reported to the healthcare facility infection control officer and the local public health authorities at once. If the patient dies, special precautions are recommended for autopsy and handling of the human remains.

\section{Smallpox (Variola) and Monkeypox}

Smallpox is an ancient and serious illness caused by variola virus, a large DNA virus in the Orthopoxvirus genus and Poxviridae family, and is primarily of historical significance, although the risk of a bioterrorism event involving smallpox remains a real concern. While many patients infected with smallpox survived, often with scars on their body or blindness, the mortality rate historically was approximately $30 \%$. The last known case of naturally occurring smallpox in the United States was documented in 1949 and globally occurred in 1977 [90].

Monkeypox is a member of the same virus genus and family as smallpox, and was discovered in 1958 in monkey colonies [91]. The first human case was reported in 1970 in Africa, in the Democratic Republic of Congo, and in 2003 an outbreak spread to the United States. Given this relatively recent emergence, clinicians should be vigilant for new cases of monkeypox. 
Smallpox is spread from human-to-human through respiratory droplets during coughing and sneezing in the early stage, and via their sores in the mouth and on the skin, once the disease has become established. Patients are contagious until the last smallpox lesion scab crusts over and falls off. It is also possible for smallpox to be transmitted via the airborne route and on fomites such as linens that were in contact with smallpox lesions. There is no known animal or insect vector for smallpox.

Monkeypox is transmitted from person to person through close contact with bodily fluids or large respiratory droplets; contact with fomites or animals, such as African rodents or prairie dogs, infected with monkeypox may also lead to human disease.

Smallpox can be suspected in children with known contact with someone who had smallpox (e.g., in the event of a bioterrorism event); however, healthcare personnel should be vigilant for a possible first or sentinel case of this highly contagious disease and suspect it in any acutely ill patient with an acute, generalized pustular rash. The illness may have several stages, first starting with high fever, myalgias, and vomiting. The first stage is followed by the early rash stage, with lesions on the tongue, in the mouth, and then on the skin, which spread rapidly to all parts of the body, in the same stage or time frame. The pustular rash stage then occurs, and within 2-3 weeks, the lesions crust into scabs and then fall off. Once all scabs have fallen off, the patient is no longer contagious. Smallpox rarely if ever causes significant lymphadenopathy.

Monkeypox illness may cause fever, headache, myalgias, and significant lymphadenopathy. The rash associated with monkeypox begins within 1-3 days after the constitutional symptoms and usually progresses, similar to smallpox, through the stages of macules, papules, vesicles, pustules, and scabs. The pustular rash stage lasts 2-3 weeks; the lesions crust into scabs and then fall off. Similar to small pox, the patient is no longer contagious once all scabs have fallen off. Monkeypox can be a severe illness, with a mortality rate of approximately $10 \%$.

Smallpox or monkeypox infection may be confirmed using special virus isolation techniques or PCR identification of specific viral DNA in a clinical specimen at a public health laboratory. Electron microscopy of a lesion may provide presumptive identification if orthopoxvirus virions are detected.

Treatment of smallpox or monkeypox includes antiviral treatment with antivirals such as tecovirimat, cidofovir, or brincidofovir, as well as supportive care with fluids and respiratory support, as needed. It is not recommended to give vaccinia immune globulin (VIG) for treatment of established disease caused by smallpox. It is not known if VIG can be beneficial in the treatment of monkeypox disease. Prior immunization or postexposure prophylaxis with the smallpox vaccine given within 3-7 days of exposure may provide protection against smallpox and monkeypox infection or severe disease. In patients with severe immune deficiency who cannot receive smallpox vaccine, use of VIG may be beneficial for postexposure prophylaxis.

Patients suspected or proven to be infected with smallpox virus or monkeypox virus should be isolated with standard, contact, and droplet precautions, preferably in an AIIR or SIU, if available. The patient should wear a mask placed over the nose and mouth, and their exposed skin with lesions covered with a sheet or gown or 
linens. Only specially trained, essential personnel should enter the hospital room to care for the patient, and a log of all persons should be maintained, and their symptoms monitored for fever, cough or other acute illnesses for 14 days after contact with the patient. Similar care regarding use of PPE, the generation of aerosols, the disposal of waste, and care of deceased patients used for patients with EVD apply to those with known or proven smallpox/monkeypox. Patients suspected or proven to be infected with either smallpox or monkeypox should be reported to the healthcare facility infection control officer and the local public health authorities immediately.

\section{Prions}

Human prion diseases, also called the transmissible spongiform encephalopathies, are very rare, uniformly fatal neurodegenerative disorders. These naturally occurring diseases include Creutzfeldt-Jakob disease (CJD), fatal insomnia, and Gerstmann-Straussler-Scheinker syndrome. Iatrogenic CJD may occur by nosocomial prion transmission after contaminated growth hormone injections, cadaveric dura mater graft, stereotactic EEG electrodes and other neurosurgical procedures, ophthalmologic procedures such as corneal transplants, or blood product transfusions [92]. Prions are small, highly resilient proteins which are capable of selfpropagation via autocatalytic templating and are highly resistant to conventional methods of decontamination. The presence of prion-contaminated instruments in the operating room, especially when neurosurgical and ophthalmologic procedures are performed, poses a rare but potentially serious risk of healthcare-associated transmission.

The diagnosis of CJD, and other prion disorders, is most reliably established by examination of brain tissue obtained by brain biopsy or at autopsy. Noninvasive diagnostic tests are under investigation. The prion disorders are uniformly fatal and no treatment is available except supportive therapies.

Patients suspected to have or diagnosed with a prion disease, such as CJD, do not require special isolation, and standard precautions are indicated for routine, noninvasive, patient care encounters. However, if patients require invasive procedures, tissues such as the brain, eye, and spinal cord, as well as the surgical instruments in contact with these tissues, should be considered to be highly infectious. During procedures in patients with known or suspected prion disease, protective measures should include a minimum of healthcare workers in the operating room, covering all non-disposable, multiple-use instruments, employing single-use equipment whenever possible, unidirectional flow of instruments, disposal of all single-use items by incineration, and thorough cleaning of all work surfaces.

Prions are highly resistant to chemical disinfectants such as alcohol, ammonia, and formalin, as well as boiling, dry heating, and ultraviolet or microwave exposure. Incineration is probably the most effective means of decontamination; however, some experts feel thorough cleaning with concentrated bleach or sodium hydroxide for an hour, followed by prolonged autoclaving, may be sufficient to decrease 
infectivity of prion-contaminated surgical instruments. Special handling for autopsy and body remains should also be followed. The WHO has detailed infection control guidelines and practices for prion infection [93].

\section{References}

1. Rubin LG, Kohn N, Nullet S, Hill M. Reduction in rate of nosocomial respiratory virus infections in a children's hospital associated with enhanced isolation precautions. Infect Control Hosp Epidemiol. 2018;39(2):152-6.

2. Goldmann DA. Epidemiology and prevention of pediatric viral respiratory infections in healthcare institutions. Emerg Infect Dis. 2001;7(2):249-53.

3. Hutspardol S, Essa M, Richardson S, Schechter T, Ali M, Krueger J, et al. Significant transplantation-related mortality from respiratory virus infections within the first one hundred days in children after hematopoietic stem cell transplantation. Biol Blood Marrow Transplant. 2015;21(10):1802-7.

4. Huskins C, Shaklee-Sammons J, Coffin S. Health-care associated infections. In: Cherry J, Harrison G, Kaplan S, Steinbach W, Hotez P, editors. Feigin and Cherry's textbook of pediatric infectious diseases. Philadelphia: Elsevier; 2018. p. 2514-42.

5. Quach C, Shah R, Rubin LG. Burden of healthcare-associated viral respiratory infections in children's hospitals. J Pediatric Infect Dis Soc. 2018;7(1):18-24.

6. Verboon-Maciolek MA, Krediet TG, Gerards LJ, Fleer A, van Loon TM. Clinical and epidemiologic characteristics of viral infections in a neonatal intensive care unit during a 12-year period. Pediatr Infect Dis J. 2005;24(10):901-4.

7. D'Arcy N, Cloutman-Green E, Klein N, Spratt DA. Environmental viral contamination in a pediatric hospital outpatient waiting area: implications for infection control. Am J Infect Control. 2014;42(8):856-60.

8. Halasa NB, Williams JV, Wilson GJ, Walsh WF, Schaffner W, Wright PF. Medical and economic impact of a respiratory syncytial virus outbreak in a neonatal intensive care unit. Pediatr Infect Dis J. 2005;24(12):1040-4.

9. Thorburn K, Eisenhut M, Riordan A. Mortality and morbidity of nosocomial respiratory syncytial virus (RSV) infection in ventilated children--a ten year perspective. Minerva Anestesiol. 2012;78(7):782.

10. Thorburn K, Kerr S, Taylor N, van Saene HK. RSV outbreak in a paediatric intensive care unit. J Hosp Infect. 2004;57(3):194-201.

11. Taylor GS, Vipond IB, Caul EO. Molecular epidemiology of outbreak of respiratory syncytial virus within bone marrow transplantation unit. J Clin Microbiol. 2001;39(2):801-3.

12. Shah DP, Ghantoji SS, Shah JN, El Taoum KK, Jiang Y, Popat U, et al. Impact of aerosolized ribavirin on mortality in 280 allogeneic haematopoietic stem cell transplant recipients with respiratory syncytial virus infections. J Antimicrob Chemother. 2013;68(8):1872-80.

13. Burrows FS, Carlos LM, Benzimra M, Marriott DJ, Havryk AP, Plit ML, et al. Oral ribavirin for respiratory syncytial virus infection after lung transplantation: efficacy and cost-efficiency. J Heart Lung Transplant. 2015;34(7):958-62.

14. Kulkarni H, Smith CM, Lee Ddo H, Hirst RA, Easton AJ, O’Callaghan C. Evidence of respiratory syncytial virus spread by aerosol. Time to revisit infection control strategies? Am J Respir Crit Care Med. 2016;194(3):308-16.

15. Sung AD, Sung JAM, Thomas S, Hyslop T, Gasparetto C, Long G, et al. Universal mask usage for reduction of respiratory viral infections after stem cell transplant: a prospective trial. Clin Infect Dis. 2016;63(8):999-1006.

16. Sokol KA, De la Vega-Diaz I, Edmondson-Martin K, Kim S, Tindle S, Wallach F, et al. Masks for prevention of respiratory viruses on the BMT unit: results of a quality initiative. Transpl Infect Dis. 2016;18(6):965-7. 
17. Sim SA, Leung VKY, Ritchie D, Slavin MA, Sullivan SG, Teh BW. Viral respiratory tract infections in allogeneic hematopoietic stem cell transplantation recipients in the era of molecular testing. Biol Blood Marrow Transplant. 2018;24(7):1490-6.

18. Kakiuchi S, Tsuji M, Nishimura H, Wang L, Takayama-Ito M, Kinoshita H, et al. Human parainfluenza virus type 3 infections in patients with hematopoietic stem cell transplants: the mode of nosocomial infections and prognosis. Jpn J Infect Dis. 2018;71(2):109-15.

19. Casey J, Morris K, Narayana M, Nakagaki M, Kennedy GA. Oral ribavirin for treatment of respiratory syncitial virus and parainfluenza 3 virus infections post allogeneic haematopoietic stem cell transplantation. Bone Marrow Transplant. 2013;48(12):1558-61.

20. Kim S, Sung H, Im HJ, Hong SJ, Kim MN. Molecular epidemiological investigation of a nosocomial outbreak of human metapneumovirus infection in a pediatric hemato-oncology patient population. J Clin Microbiol. 2009;47(4):1221-4.

21. Hoellein A, Hecker J, Hoffmann D, Gottle F, Protzer U, Peschel C, et al. Serious outbreak of human metapneumovirus in patients with hematologic malignancies. Leuk Lymphoma. 2016;57(3):623-7.

22. Houlihan C, Frampton D, Ferns RB, Raffle J, Grant P, Reidy M, et al. The use of whole genome sequencing in the investigation of a nosocomial influenza virus outbreak. J Infect Dis. 2018 [E pub ahead of print].

23. Bearden A, Friedrich TC, Goldberg TL, Byrne B, Spiegel C, Schult P, et al. An outbreak of the 2009 influenza a (H1N1) virus in a children's hospital. Influenza Other Respir Viruses. 2012;6(5):374-9.

24. Fanella ST, Pinto MA, Bridger NA, Bullard JM, Coombs JM, Crockett ME, et al. Pandemic (H1N1) 2009 influenza in hospitalized children in Manitoba: nosocomial transmission and lessons learned from the first wave. Infect Control Hosp Epidemiol. 2011;32(5):435-43.

25. Pollara CP, Piccinelli G, Rossi G, Cattaneo C, Perandin F, Corbellini S, et al. Nosocomial outbreak of the pandemic Influenza A (H1N1) 2009 in critical hematologic patients during seasonal influenza 2010-2011: detection of oseltamivir resistant variant viruses. BMC Infect Dis. 2013;13:127.

26. Xiao S, Tang JW, Hui DS, Lei H, Yu H, Li Y. Probable transmission routes of the influenza virus in a nosocomial outbreak. Epidemiol Infect. 2018;146(9):1114-22.

27. Feemster K, Localio R, Grundmeier R, Metlay JP, Coffin SE. Incidence of healthcareassociated influenza-like illness after a primary care encounter among young children. J Pediatric Infect Dis Soc. 2018 [E pub ahead of print].

28. Bhadelia N, Sonti R, McCarthy JW, Vorenkamp J, Jia H, Saiman L, et al. Impact of the 2009 influenza A $(\mathrm{H} 1 \mathrm{~N} 1)$ pandemic on healthcare workers at a tertiary care center in New York City. Infect Control Hosp Epidemiol. 2013;34(8):825-31.

29. Steiner M, Strassl R, Straub J, Bohm J, Popow-Kraupp T, Berger A. Nosocomial rhinovirus infection in preterm infants. Pediatr Infect Dis J. 2012;31(12):1302-4.

30. Reid AB, Anderson TL, Cooley L, Williamson J, McGregor AR. An outbreak of human rhinovirus species $\mathrm{C}$ infections in a neonatal intensive care unit. Pediatr Infect Dis $\mathrm{J}$. 2011;30(12):1096-5.

31. Reese SM, Thompson M, Price CS, Young HL. Evidence of nosocomial transmission of human rhinovirus in a neonatal intensive care unit. Am J Infect Control. 2016;44(3):355-7.

32. Centers for Disease Control and Prevention. Enterovirus D68. https://www.cdc.gov/non-polioenterovirus/about/EV-D68.html. Published 2018. Accessed 13 June 2018.

33. Gralton J, McLaws ML, Rawlinson WD. Personal clothing as a potential vector of respiratory virus transmission in childcare settings. J Med Virol. 2015;87(6):925-30.

34. Ersoy Y, Otlu B, Turkcuoglu P, Yetkin F, Aker S, Kuzucu C. Outbreak of adenovirus serotype 8 conjunctivitis in preterm infants in a neonatal intensive care unit. J Hosp Infect. 2012;80(2):144-9.

35. Palomino MA, Larranaga C, Avendano LF. Hospital-acquired adenovirus $7 \mathrm{~h}$ infantile respiratory infection in Chile. Pediatr Infect Dis J. 2000;19(6):527-31. 
36. Uzuner H, Karadenizli A, Kadir Er D, Osmani A. Investigation of the efficacy of alcohol-based solutions on adenovirus serotypes 8,19 and 37 , the common cause of epidemic keratoconjunctivitis, after an adenovirus outbreak occurred in the hospital. J Hosp Infect. 2018 [E pub ahead of print].

37. Woodman TJ, Coats DK, Paysse EA, Demmler GJ, Rossmann SN. Disinfection of eyelid speculums for retinopathy of prematurity examination. Arch Ophthalmol. 1998;116(9):1195-8.

38. Junk AK, Chen PP, Lin SC, Nouri-Mahdavi K, Radhakrishnan S, Singh K, et al. Disinfection of Tonometers: a report by the American academy of ophthalmology. Ophthalmology. 2017;124(12):1867-75.

39. Cloutman-Green E, Canales M, Pankhurst L, Evenor T, Malone D, Klein N, et al. Development and implementation of a cleaning standard algorithm to monitor the efficiency of terminal cleaning in removing adenovirus within a pediatric hematopoietic stem cell transplantation unit. Am J Infect Control. 2015;43(9):997-9.

40. Weber DJ, Anderson D, Rutala WA. The role of the surface environment in healthcareassociated infections. Curr Opin Infect Dis. 2013;26(4):338-44.

41. Saadi H, Pagnier I, Colson P, Cherif JK, Beji M, Boughalmi M, et al. First isolation of Mimivirus in a patient with pneumonia. Clin Infect Dis. 2013;57(4):e127-34.

42. Vincent A, La Scola B, Papazian L. Advances in Mimivirus pathogenicity. Intervirology. 2010;53(5):304-9.

43. dos Santos Silva LK, Arantes TS, Andrade KR, Lima Rodrigues RA, Miranda Boratto PV, de Freitas Almeida GM, et al. High positivity of mimivirus in inanimate surfaces of a hospital respiratory-isolation facility, Brazil. J Clin Virol. 2015;66:62-5.

44. Bousbia S, Papazian L, Saux P, Forel JM, Auffray JP, Martin C, et al. Serologic prevalence of amoeba-associated microorganisms in intensive care unit pneumonia patients. PLoS One. 2013;8(3):e58111.

45. Anderson RM, May RM. Directly transmitted infections diseases: control by vaccination. Science. 1982;215(4536):1053-60.

46. Guerra FM, Bolotin S, Lim G, Heffernan J, Deeks SL, Li Y, et al. The basic reproduction number (R0) of measles: a systematic review. Lancet Infect Dis. 2017;17(12):e420-8.

47. Botelho-Nevers E, Gautret P, Biellik R, Brouqui P. Nosocomial transmission of measles: an updated review. Vaccine. 2012;30(27):3996-4001.

48. Farizo KM, Stehr-Green PA, Simpson DM, Markowitz LE. Pediatric emergency room visits: a risk factor for acquiring measles. Pediatrics. 1991;87(1):74-9.

49. Centers for Disease Control and Prevention. Hospital-associated measles outbreak Pennsylvania, March-April 2009. MMWR Morb Mortal Wkly Rep. 2012;61(2):30-2.

50. American Academy of Pediatrics. Red book report of the committee on infectious diseases. 31st ed. Itasca: American Academy of Pediatrics; 2018.

51. Kutty PK, Kyaw MH, Dayan GH, Brady MT, Bocchini JA, Reef SE, et al. Guidance for isolation precautions for mumps in the United States: a review of the scientific basis for policy change. Clin Infect Dis. 2010;50(12):1619-28.

52. Fischer PR, Brunetti C, Welch V, Christenson JC. Nosocomial mumps: report of an outbreak and its control. Am J Infect Control. 1996;24(1):13-8.

53. Gilroy SA, Domachowske JB, Johnson L, Martin D, Gross S, Bode M, et al. Mumps exposure of a health care provider working in a neonatal intensive care unit leads to a hospital-wide effort that prevented an outbreak. Am J Infect Control. 2011;39(8):697-700.

54. Sawyer MH, Chamberlin CJ, Wu YN, Aintablian N, Wallace MR. Detection of varicella-zoster virus DNA in air samples from hospital rooms. J Infect Dis. 1994;169(1):91-4.

55. Yoshikawa T, Ihira M, Suzuki K, Suga S, Tomitaka A, Ueda H, et al. Rapid contamination of the environments with varicella-zoster virus DNA from a patient with herpes zoster. J Med Virol. 2001;63(1):64-6.

56. Depledge DP, Brown J, Macanovic J, Underhill G, Breuer J. Viral genome sequencing proves nosocomial transmission of fatal varicella. J Infect Dis. 2016;214(9):1399-402. 
57. Juhl D, Ozdemir M, Dreier J, Gorg S, Hennig H. Look-back study on recipients of parvovirus B19 (B19V) DNA-positive blood components. Vox Sang. 2015;109(4):305-11.

58. Sungkate S, Phongsamart W, Rungmaitree S, Lapphra K, Wittawatmongkol O, Pumsuwan V, et al. Human parvovirus B19 nosocomial outbreak in healthcare personnel in a paediatric ward at a national tertiary referral centre in Thailand. J Hosp Infect. 2017;96(2):163-7.

59. Standaert B, Strens D, Li X, Schecroun N, Raes M. The sustained rotavirus vaccination impact on nosocomial infection, duration of hospital stay, and age: the RotaBIS study (2005-2012). Infect Dis Ther. 2016;5(4):509-24.

60. Fraenkel CJ, Inghammar M, Johansson PJ, Bottiger B. Incidence of hospital norovirus outbreaks and infections using 2 surveillance methods in Sweden. Infect Control Hosp Epidemiol. 2017;38(1):96-102.

61. Turcios-Ruiz RM, Axelrod P, St John K, Bullitt E, Donahue J, Robinson N, et al. Outbreak of necrotizing enterocolitis caused by norovirus in a neonatal intensive care unit. J Pediatr. 2008;153(3):339-44.

62. de Jong EP, van den Beuken MGA, van Elzakker EPM, Wolthers KC, Sprij AJ, Lopriore E, et al. Epidemiology of Sepsis-like illness in young infants: major role of enterovirus and human parechovirus. Pediatr Infect Dis J. 2018;37(2):113-8.

63. Ferreras Antolin L, Kadambari S, Braccio S, Tang JW, Xerry J, Allen DJ, et al. Increased detection of human parechovirus infection in infants in England during 2016: epidemiology and clinical characteristics. Arch Dis Child. 2018 [E pub ahead of print].

64. Abedi GR, Watson JT, Nix WA, Oberste MS, Gerber SI. Enterovirus and Parechovirus surveillance - United States, 2014-2016. MMWR Morb Mortal Wkly Rep. 2018;67(18):515-8.

65. Strenger V, Diedrich S, Boettcher S, Richter S, Maritschnegg P, Gangl D, et al. Nosocomial outbreak of Parechovirus 3 infection among newborns, Austria, 2014. Emerg Infect Dis. 2016;22(9):1631-4.

66. Pankhurst L, Cloutman-Green E, Canales M, D'Arcy N, Hartley JC. Routine monitoring of adenovirus and norovirus within the health care environment. Am J Infect Control. 2014;42(11):1229-32.

67. Rodriguez-Baez N, O'Brien R, Qiu SQ, Bass DM. Astrovirus, adenovirus, and rotavirus in hospitalized children: prevalence and association with gastroenteritis. J Pediatr Gastroenterol Nutr. 2002;35(1):64-8.

68. Dodhia S, Baxter PC, Ye F, Pitman MJ. Investigation of the presence of HPV on KTP laser fibers following KTP laser treatment of papilloma. Laryngoscope. 2018;128(4):926-8.

69. Casalegno JS, Le Bail CK, Eibach D, Valdeyron ML, Lamblin G, Jacquemoud H, et al. High risk HPV contamination of endocavity vaginal ultrasound probes: an underestimated route of nosocomial infection? PLoS One. 2012;7(10):e48137.

70. Gallay C, Miranda E, Schaefer S, Catarino R, Jacot-Guillarmod M, Menoud PA, et al. Human papillomavirus (HPV) contamination of gynaecological equipment. Sex Transm Infect. 2016;92(1):19-23.

71. Saugel B, Jakobus J, Huber W, Hoffmann D, Holzapfel K, Protzer U, et al. Herpes simplex virus in bronchoalveolar lavage fluid of medical intensive care unit patients: association with lung injury and outcome. J Crit Care. 2016;32:138-44.

72. Walton AH, Muenzer JT, Rasche D, Boomer JS, Sato B, Brownstein BH, et al. Reactivation of multiple viruses in patients with sepsis. PLoS One. 2014;9(2):e98819.

73. Lepiller Q, Sueur C, Solis M, Barth H, Glady L, Lefebvre F, et al. Clinical relevance of herpes simplex virus viremia in intensive care unit patients. J Infect. 2015;71(1):93-100.

74. Farooq AV, Shukla D. Corneal latency and transmission of herpes simplex virus-1. Future Virol. 2011;6(1):101-8.

75. Hutchinson AK, Coats DK, Langdale LM, Steed LL, Demmler G, Saunders RA. Disinfection of eyelid specula with chlorhexidine gluconate (Hibiclens) after examinations for retinopathy of prematurity. Arch Ophthalmol. 2000;118(6):786-9.

76. Drew WL, Tegtmeier G, Alter HJ, Laycock ME, Miner RC, Busch MP. Frequency and duration of plasma CMV viremia in seroconverting blood donors and recipients. Transfusion. 2003;43(3):309-13. 
77. Lachance P, Chen J, Featherstone R, Sligl WI. Association between cytomegalovirus reactivation and clinical outcomes in immunocompetent critically ill patients: a systematic review and meta-analysis. Open Forum Infect Dis. 2017;4(2):ofx029.

78. Limaye AP, Kirby KA, Rubenfeld GD, Leisenring WM, Bulger EM, Neff MJ, et al. Cytomegalovirus reactivation in critically ill immunocompetent patients. JAMA. 2008;300(4):413-22.

79. Josephson CD, Caliendo AM, Easley KA, Knezevic A, Shenvi N, Hinkes MT, et al. Blood transfusion and breast milk transmission of cytomegalovirus in very low-birth-weight infants: a prospective cohort study. JAMA Pediatr. 2014;168(11):1054-62.

80. Lanzieri TM, Dollard SC, Josephson CD, Schmid DS, Bialek SR. Breast milk-acquired cytomegalovirus infection and disease in VLBW and premature infants. Pediatrics. 2013;131(6):e1937-45.

81. Civardi E, Tzialla C, Baldanti F, Strocchio L, Manzoni P, Stronati M. Viral outbreaks in neonatal intensive care units: what we do not know. Am J Infect Control. 2013;41(10):854-6.

82. Centers for Disease Control and Prevention. Guidance for persons who may have been exposed to SARS. https://www.cdc.gov/sars/infection/exposure.html. Published 2005. Accessed 13 June 2018.

83. Centers for Disease Control and Prevention. Interim infection prevention and control recommendations for hospitalized patients with Middle East respiratory syndrome coronavirus (MERS-CoV). https://www.cdc.gov/coronavirus/mers/infection-prevention-control.html. Published 2015. Accessed 13 June 2018.

84. Assiri A, Al-Tawfiq JA, Al-Rabeeah AA, Al-Rabiah FA, Al-Hajjar S, Al-Barrak A, et al. Epidemiological, demographic, and clinical characteristics of 47 cases of Middle East respiratory syndrome coronavirus disease from Saudi Arabia: a descriptive study. Lancet Infect Dis. 2013;13(9):752-61.

85. Ahmed AE. Estimating survival rates in MERS-CoV patients 14 and 45 days after experiencing symptoms and determining the differences in survival rates by demographic data, disease characteristics and regions: a worldwide study. Epidemiol Infect. 2018;146(4):489-95.

86. Hastings DL, Tokars JI, Abdel Aziz IZ, Alkhaldi KZ, Bensadek AT, Alraddadi BM, et al. Outbreak of Middle East respiratory syndrome at tertiary care hospital, Jeddah, Saudi Arabia, 2014. Emerg Infect Dis. 2016;22(5):794-801.

87. Sassi HP, Reynolds KA, Pepper IL, Gerba CP. Evaluation of hospital-grade disinfectants on viral deposition on surfaces after toilet flushing. Am J Infect Control. 2018;46(5):507-11.

88. Arrington A, Hilmers D, Campbell J, Harrison G. Filoviral hemorrhagic fever: Marburg and Ebola virus fevers. In: Cherry J, Harrison G, Kaplan S, Steinbach W, Hotez P, editors. Feigin and Cherry's textbook of pediatric infectious diseases. 8th ed. Philadelphia: Elsevier; 2018. p. $1839-41$.

89. Centers for Disease Control and Prevention. Guidance on personal protective equipment (PPE) to be used by healthcare workers during management of patients with confirmed ebola or persons under investigation (PUIs) for ebola who are clinically unstable or have bleeding, vomiting or diarrhea in US hospitals, including procedures for donning and doffing PPE. https:// www.cdc.gov/vhf/ebola/healthcare-us/ppe/guidance.html. Published 2015. Accessed 13 June 2018.

90. Centers for Disease Control and Prevention. Smallpox. https://www.cdc.gov/smallpox/clinicians/index.html. Published 2017. Accessed 13 June 2018.

91. Centers for Disease Control and Prevention. Monkeypox. https://www.cdc.gov/poxvirus/monkeypox/clinicians/infection-control-hospital.html. Published 2015. Accessed 13 June 2018.

92. Bonda DJ, Manjila S, Mehndiratta P, Khan F, Miller BR, Onwuzulike K, et al. Human prion diseases: surgical lessons learned from iatrogenic prion transmission. Neurosurg Focus. 2016;41(1):E10.

93. World Health Organization. WHO infection control guidelines for transmissible spongiform encephalopathies. Geneva: World Health Organization (WHO); 1999. 